\title{
Semi-Field Evaluation of some Slow-Release Insecticide Formulations against the Dengue Fever Mosquito Aedes aegypti (L)
}

\author{
N.A. Alkenani, ${ }^{1}$ KH. M. AL-Ghamdi ${ }^{1}$, M.S. Saleh ${ }^{2}$ and J.A. Mahyoub ${ }^{1}$
}

\begin{abstract}
Semi-field trials were conducted to evaluate the efficacy of slow-release formulations (SRFs) of Bactimos briquets, Spinosad tablets, Altosid briquets and Dudim tablets against mosquito larvae of Aedes aegypti. The records showed that SRF treatments provided long-term effective control against mosquito larvae using a single application of the test formulations. Effective control with $\mathbf{9 0 - 1 0 0 \%}$ inhibition of adult emergence was obtained for 4 , 9, 10 and 12 weeks post-treatment by using SRFs of Bactimos, Spinosad, Altosid and Dudim, respectively. On the other hand, the results showed that larval treatments with the test SRFs affected the blood feeding activity and reproductive capacity of mosquito adult survivors.
\end{abstract}

Key words: Aedes aegypti, slow-release formulations, semi-field trials, blood feeding activity, reproductive capacity.

\section{INTRODUCTION}

Currently, dengue fever is the most important arthropod-borne viral disease in different parts of the world. Aedes aegypti is generally recognized as the primary vector of dengue viruses causing 50 million cases of infection and 300,000 deaths each year in tropical and subtropical areas (Darriet et al., 2010).

With the current trends in dengue incidence worldwide and without an effective vaccine, it is expected that the widespread use of insecticides will continue. Many insecticide formulations have been developed and tested for their efficacy against a wide spectrum of mosquito vectors. In this concern, a great impetus has been given to the use of slow-release insecticide formulations against mosquito larvae (WHO, 2005). Such formulations are likely to enhance residual larvicidal activity via greater stability and maximized contact with the target mosquito larvae (Mulla et al., 1988; Cornell et al., 2000; Bond et al., 2004, Seng et al., 2008; Jacups et al., 2014).

The present research work was planned to evaluate the larvicidal efficacy of four slow-release formulations of bacterial insecticides and insect growth regulators (IGRs) against mosquito larvae of $A$. aegypti, the primary vector of dengue fever in Jeddah governorate, Saudi Arabia. The blood feeding activity and reproductive capacity of mosquito adult survived from larval treatments with the tested formulations were also studied.

\section{MATERIALS AND METHODS \\ Mosquito strain}

Tests were performed on a field strain of $A$. aegypti (L.) raised from wild larvae, collected from Al-Jamaeh District, Jeddah governorate, Saudi Arabia, and had been maintained under laboratory conditions of $27 \pm 1^{\circ} \mathrm{C}$ and $70 \pm 5 \%$ R.H. with 14: 10 (L:D). The larvae were reared until pupation and adult emergence took place for maintaining the stock culture.

\section{SRFs tested}

The following SRFs were used:

1- Two SRFs of bacterial insecticides: Bactiomos briquets (Bacillus thuringiensis israelensis, 7000 ITU; $10 \%$ a.i., briquet weight $12.5 \mathrm{gm}$, supplied by Summit Chem. Co., Baltimore, M.D., USA) and Spionsad DT tablets (Saccharopolyspora spinosa, $7.48 \%$ a.i., tablet weight $1.37 \mathrm{mg}$, provided by Clark Company, Roselle, IL, USA).

2- Two SRFs of IGRs: Altosid XR-briquets (Methoprene 2.1\% a.i., briquet weight $48 \mathrm{gm}$, proided by Zoecon, USA) and Dudim DT tablets (Diflubenzuron $2 \%$ a.i., tablet weight 2 gm, supplied by DGM Italia SrL).

\section{Experiments}

Semi-field trials were conducted at dengue mosquito research station, Dept. of Biological Science, Fac. of Science, King Abdul-Aziz Univ., Jeddah, Saudi Arabia. Experiments were carried out in white plastic pools $(50 \times 50 \times 30 \mathrm{~cm})$ containing $30 \mathrm{~L}$ of tap water. The pools were placed in the shade under a roof and were kept covered with muslin cloth sheets to prevent debris and ovipositon by wild mosquitoes. Each pool received a batch of 25 third instar larvae of $A$. aegypti and the test formulation. The dosage of each formulation required for larval treatments (Aquarter pieces, $3.2 \mathrm{gm}$ of Bactioms briquet; $0.2 \mathrm{gm}$ of Spinosad tablet; $7 \mathrm{gm}$ of Altosid briquet and $0.3 \mathrm{gm}$ of Dudim tablet) was determined according to the recommended dosages for

\footnotetext{
1 Dept. of Biological Science, Fac. of Science,

King Abdul - Aziz Univ., Jeddah, KSA.

${ }^{2}$ Dept. of Applied Entomology, Fac. of Agriculture,

Alexandria Univ., Alex., Egypt.

E-mail: Dipter2012@gmail.com

Received May 6, 2015, Accepted june 2, 2015
} 
field control. Pools without formulations were used as controls. The larvae were given the usual larval food during the tests. Water was slowly added to the pools every other day to compensate evaporation. New live batches of $3^{\text {rd }}$ larval instars of $A$. aegypti were added weekly to the test pools. All treatments and controls were replicated four times. Any pupae produced were transferred to small plastic cups containing water and placed in adult cages for emergence. The efficacy of the test formulations was calculated as the number of emerging adults compared to the initial number of larvae added or the inhibition of emergence (\%IE). The assessment of effectiveness was made at weekly intervals until the level of efficacy decrease to $<50 \%$ IE.

Subsequent trials were also carried out to study the delayed effects of larval treatments with the test formulations on the blood feeding activity and reproductive potential of mosquito adults that emerged from these treatments. Adult survivors were isolated in clean cages. Four days later, emerged females were subject to a pigeon as a source of the blood meal. The percentage of biting was estimated after one hour and was expressed as the number of blood-fed females / total number of test females $\times 100$. Afterwards, each engorged female was kept with a male in small plastic cups, half-filled with water and covered with Nylon cloth held in place with a rubber band. They were fed on a $10 \%$ sugar solution through the Nylon cloth using cotton pads. The reproductive potential of mosquitoes (based on egg production and egg hatchability) was also considered for the $1^{\text {st }}$ gonotrophic cycle. Differences between treatments and controls were compared and analysed using the t-test.

\section{RESULTS AND DISCUSSION}

The efficacy of two bacterial insecticides Bactioms and Spionsad as SRFs against $3^{r d}$ instar mosquito larvae of $A$. aegypti is shown in Table 1 and illustrated by Fig. 1. The effective control was defined as $90-100 \%$ inhibition of adult emergence (\%IE).

The results showed that larval treatments with Bactioms briquets produced ineffective control (81\% IE) for one week post-treatment and then the formulation began to give continuous effective control with 90-100\% IE for about 4 weeks (Fig. 1). On the other hand, larval treatments with Spionsad tablets provided excellent effective control with $90-100 \%$ IE for 9 weeks posttreatments, after which its efficacy declined to $58 \%$ IE at week 12 post-treatment and 35\% IE by the end of week 17 (Fig. 1). Taking the durations of effective control into consideration, the records showed that Spinosad tablets (9 weeks) proved to be highly effective against mosquito larvae of $A$. aegypti than Bactimos briquets (4 weeks) by about 2.25 times.
Table 2 shows the larvicidal effectiveness of two IGRs Altosid and Dudim as SRFs against $A$. aegypti. The results showed that treatments with Altosid XR-briquets produced high levels of residual efficacy against the present mosquito larvae as indicated by $>90-100 \%$ IE for 10 weeks post-treatment (Fig. 2). However, satisfactory control $>85 \%$ IE was observed for 12 weeks posttreatment. On the other hand, effective control (90-100\% IE) was obtained with Dudim tablet treatments for a period of 12 weeks post-treatment, after which its effectiveness decreased to $70.2 \%$ IE at week 15 , and then fluctuated between 38.7 and $26.6 \%$ IE during the last five weeks of trials (Fig. 2). In general, these records indicate that treatment of $A$. aegypti larvae with Dudim tablets is 1.2 times more effective than Altosid briquets. This was highly pronounced on the basis of durations of effective control (90-100\% IE) of SRFs of Altosid (10 weeks) and Dudim (12 weeks). However, variations in the durations of efficacy among the test SRFs may be attributed to the differential mode of action of the active ingredients and the dosages tested (Saleh et al., 2013). Similar studies in this respect were conducted by several investigators using different SRFs of bacterial insecticides (Nasci et al., 1994; Saleh et al., 2003; Thavara et al., 2009; Tripathi et al., 2013) and IGRs (Knepper et al., 1992; Nayer et al., 2002; Seng et al., 2008; Jacups et al., 2014) against many species of mosquito vectors. They pointed out that larval treatments with SRFs provided continuous good to excellent control against different mosquito larvae for several weeks. Such SRFs may be particularly useful for application in any location near the household where water collects and remains for long period such as pond, irrigated pastures and artificial containers.

Table 3 shows the blood feeding activity $A$. aegypti mosquito females that survived from larval SRF treatments. The records indicated that the blood feeding activity of females emerged from larval treatments with Bactimos briquets (84\%) and Spinosad tablets (80\%) was reduced by about 8.7 and $16.7 \%$, respectively, when compared with their control which were in respect 92 and $96 \%$. A similar depression in the blood feeding response was obtained with mosquito females of $A$. aegypti that survival from larval treatments with Altosid briquets $(56 \%)$ and Dudim tablets $(64 \%)$ by about 36.4 and $30.4 \%$, respectively, as compared with control ones. Depression in the blood feeding activity may be due to larval SRF treatments affected the structure and function of muscles responsible for the movements of maxillae in mouth parts of female survivors (Vasuki, 1992). Similar reduced feeding responses have be reported by Saleh and Wright (1990) using Cyromazine against A. epacticus and Sithiprasasna et al. (1996) using Methoprene against Anopheles dirus. However, the reduction in blood feeding activity of mosquito 
females may led to a decrease in the number of fully engorged females and accordingly affect the reproductive capacity of mosquitoes.

The results showed that treatment of $A$. aegypti larvae with Bactioms briquets did not significantly

Table 1. Effectiveness of SRFs of Bactimos briquets and Spinosad tablets against mosquito larvae of $\boldsymbol{A}$. aegypti

\begin{tabular}{|c|c|c|c|c|c|c|c|c|}
\hline \multirow{2}{*}{$\begin{array}{l}\text { Weeks post- } \\
\text { treatment }\end{array}$} & \multicolumn{2}{|c|}{ Dead larvae* } & \multicolumn{2}{|c|}{ Pupae produced (\%) } & \multicolumn{2}{|c|}{ Adult emerged (\%) } & \multicolumn{2}{|c|}{ IE (\%) } \\
\hline & $\mathbf{B}$ & $\mathbf{S}$ & B & $\mathbf{S}$ & $\mathbf{B}$ & $\mathbf{S}$ & $\mathbf{B}$ & $\mathbf{S}$ \\
\hline 1 & 76 & 100 & 24 & 0.0 & 19 & 0.0 & 81 & 100 \\
\hline 2 & 98 & 100 & 2 & 0.0 & 1.0 & 0.0 & 98.9 & 100 \\
\hline 3 & 100 & 100 & 0.0 & 0.0 & 0.0 & 0.0 & 100 & 100 \\
\hline 4 & 96 & 100 & 4 & 0.0 & 3 & 0.0 & 96.8 & 100 \\
\hline 5 & 89 & 100 & 11 & 0.0 & 7 & 0.0 & 93 & 100 \\
\hline 6 & 71 & 93 & 29 & 7 & 21 & 5 & 79 & 95 \\
\hline 7 & 56 & 97 & 44 & 3 & 36 & 3 & 61.7 & 96.8 \\
\hline 8 & 39 & 90 & 61 & 10 & 58 & 4 & 42 & 96 \\
\hline 9 & 22 & 91 & 78 & 9 & 70 & 3 & 24.7 & 96.7 \\
\hline 10 & 24 & 83 & 76 & 17 & 73 & 13 & 20.6 & 85.9 \\
\hline 11 & 20 & 78 & 80 & 22 & 71 & 16 & 29 & 84 \\
\hline 12 & 18 & 53 & 82 & 47 & 77 & 42 & 18.1 & 58 \\
\hline 13 & & 40 & & 60 & & 51 & & 45.7 \\
\hline 14 & & 24 & & 76 & & 71 & & 29 \\
\hline 15 & & 31 & & 69 & & 66 & & 28.3 \\
\hline 16 & & 26 & & 74 & & 68 & & 32 \\
\hline 17 & & 31 & & 69 & & 65 & & 35 \\
\hline
\end{tabular}

* Four replicates, 25 larvae each; control mortalities ranged from 4-9\% IE.

$\mathrm{B}=$ Bactimos briquets; $\mathrm{S}=$ Spinosad tablets

$\mathrm{IE}=$ Inhibition of emergence, corrected for control mortalities (Abbott, 1925)

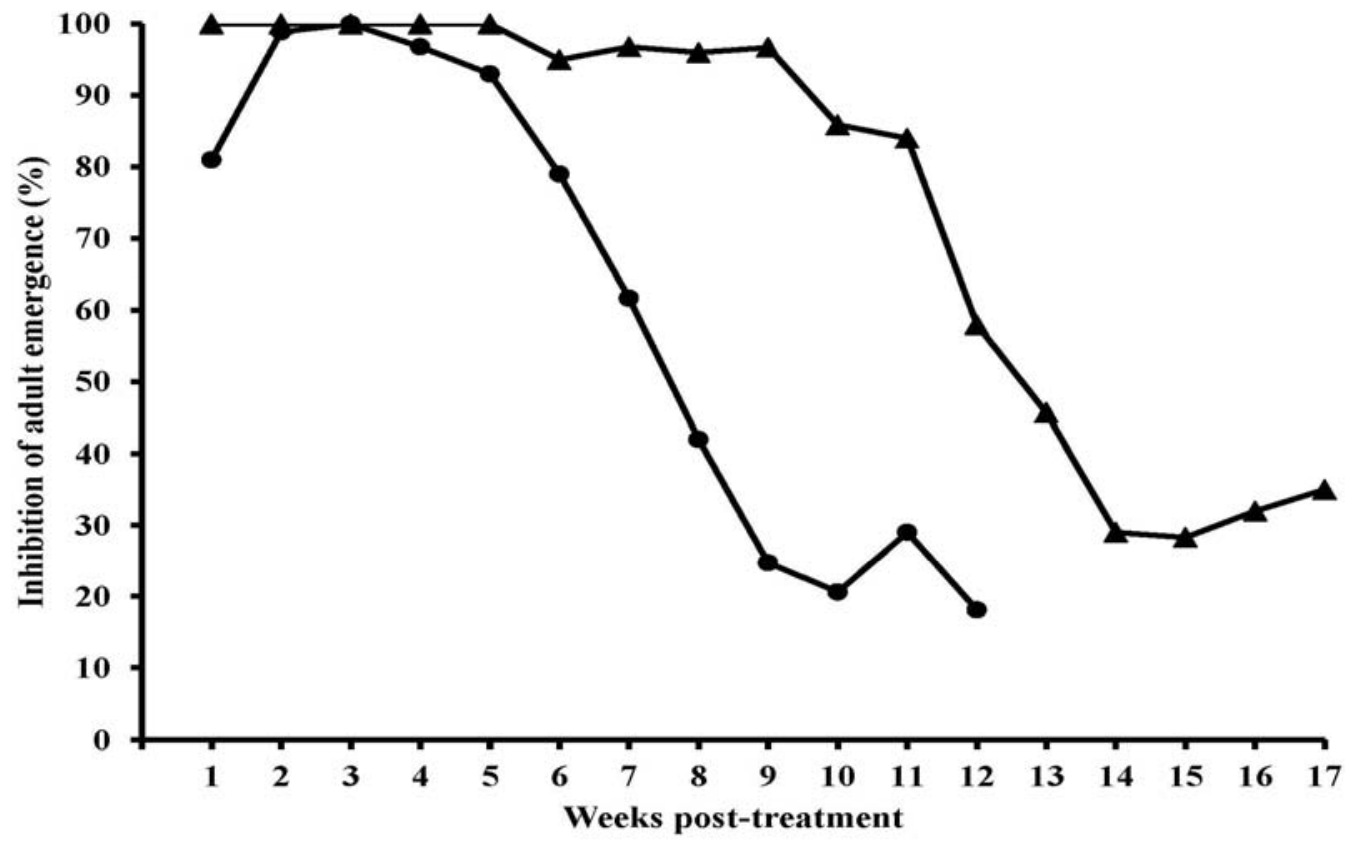


Fig. 1. Percentage emergence inhibition of $A$. aegypti after the treatment of $3^{\text {rd }}$ instar larvae with

\section{SRFs of Bactimos briquets $(-)$ and Spinosad tablets $(-\rightarrow)$}

Table 2. Effectiveness of SRFs of Altosid briquets and Dudim tablets against mosquito larvae of $A$. aegypti

\begin{tabular}{|c|c|c|c|c|c|c|c|c|}
\hline \multirow{2}{*}{$\begin{array}{c}\text { Weeks post- } \\
\text { treatment }\end{array}$} & \multicolumn{2}{|c|}{ Dead larvae* } & \multicolumn{2}{|c|}{ Pupae produced (\%) } & \multicolumn{2}{|c|}{ Adult emerged (\%) } & \multicolumn{2}{|c|}{ IE (\%) } \\
\hline & $\mathbf{A}$ & D & $\mathbf{A}$ & D & $\mathbf{A}$ & D & $\mathbf{A}$ & D \\
\hline 1 & 32 & 29 & 68 & 71 & 6 & 8 & 93.5 & 91.4 \\
\hline 2 & 41 & 38 & 59 & 62 & 0.0 & 6 & 100 & 93.5 \\
\hline 3 & 36 & 43 & 64 & 57 & 2 & 8 & 97.8 & 91.5 \\
\hline 4 & 39 & 46 & 61 & 54 & 0.0 & 9 & 100 & 90.3 \\
\hline 5 & 44 & 36 & 56 & 64 & 4 & 0.0 & 95.6 & 100 \\
\hline 6 & 32 & 54 & 68 & 46 & 4 & 8 & 95.5 & 91.1 \\
\hline 7 & 31 & 44 & 69 & 56 & 5 & 0.0 & 94.6 & 100 \\
\hline 8 & 28 & 49 & 72 & 51 & 3 & 0.0 & 96.7 & 100 \\
\hline 9 & 26 & 40 & 74 & 60 & 5 & 7 & 94.6 & 92.5 \\
\hline 10 & 30 & 32 & 70 & 68 & 6 & 5 & 93.5 & 94.6 \\
\hline 11 & 32 & 37 & 68 & 63 & 10 & 2 & 88.9 & 97.8 \\
\hline 12 & 34 & 39 & 66 & 61 & 13 & 9 & 85.5 & 90.0 \\
\hline 13 & 29 & 31 & 71 & 69 & 22 & 18 & 75.8 & 80.0 \\
\hline 14 & 26 & 28 & 74 & 72 & 51 & 21 & 45.7 & 77.6 \\
\hline 15 & 19 & 35 & 41 & 65 & 66 & 28 & 29.9 & 70.2 \\
\hline 16 & 27 & 27 & 73 & 73 & 60 & 57 & 35.5 & 38.7 \\
\hline 17 & 22 & 26 & 78 & 74 & 63 & 64 & 31.5 & 30.4 \\
\hline 18 & 19 & 18 & 81 & 82 & 74 & 66 & 17.8 & 28.3 \\
\hline 19 & & 20 & & 80 & & 74 & & 23.6 \\
\hline 20 & & 15 & & 85 & & 69 & & 26.6 \\
\hline
\end{tabular}

* Four replicates, 25 larvae each; control mortalities ranged from $6-10 \%$ IE.

$\mathrm{A}=$ Altosid briquets;

$\mathrm{D}=$ Dudim tablets

$\mathrm{IE}=$ Inhibition of emergence, corrected for control mortalities (Abbott, 1925)

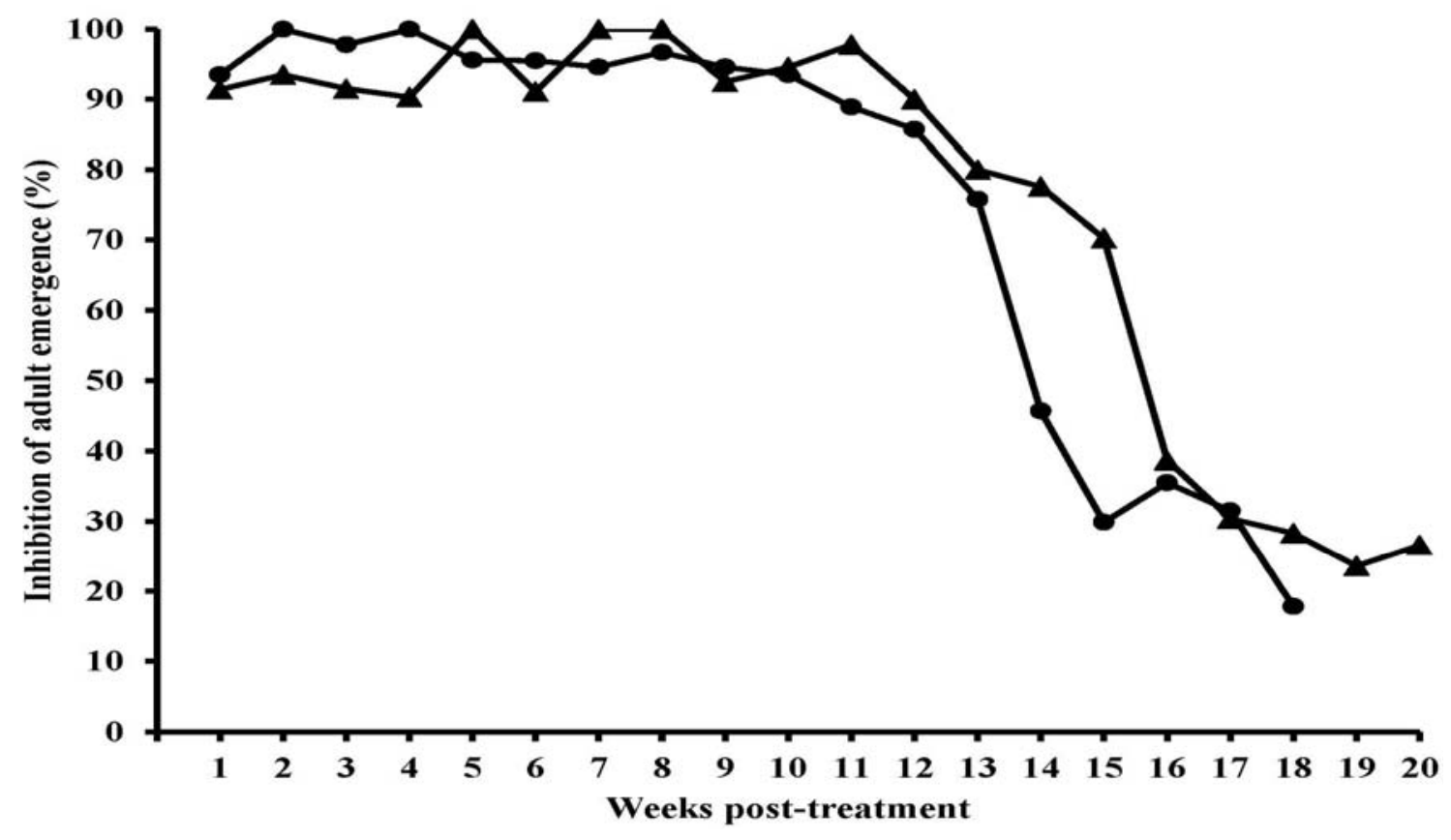


Fig. 2. Percentage emergence inhibition of $A$. aegypti after the treatment of $3^{\text {rd }}$ instar larvae with SRFs of Altosid briquets $(-)$ and Dudim tablets $(-\boldsymbol{})$

Table 3. The effect of larval treatments with SRFs on the blood feeding activity in mosquito females of $A$. aegypti that survived from these treatment

\begin{tabular}{lccccc}
\hline \multirow{2}{*}{ SRFs } & \multicolumn{2}{c}{ No. of engorged females* } & Feeding activity (\%) & \multirow{2}{*}{ Reduction (\%) } \\
\cline { 2 - 5 } & Treatment & Control & Treatment & Control & \\
\hline Bactimos briquets & 21 & 23 & 84 & 92 & 8.7 \\
\hline Spinosad tablets & 20 & 24 & 80 & 96 & 16.7 \\
\hline Altosid briquets & 14 & 22 & 56 & 88 & 36.4 \\
\hline Dudim tablets & 16 & 23 & 64 & 92 & 30.4 \\
\hline
\end{tabular}

* 25 unfed mosquito females were used.

Table 4. The effect of larval treatments with SRFs on the reproductive potential of $A$. aegypti adults that emerged from survived larvae

\begin{tabular}{|c|c|c|c|c|c|}
\hline \multirow[t]{2}{*}{ SRFs } & \multicolumn{2}{|c|}{ Egg production } & \multirow{2}{*}{$\begin{array}{l}\text { Total No. of } \\
\text { larvae } \\
\text { hatched }\end{array}$} & \multirow{2}{*}{ Hatchability (\%) } & \multirow{2}{*}{$\begin{array}{c}\text { Reduction } \\
(\%)\end{array}$} \\
\hline & Total & Mean* $*$ S.E. & & & \\
\hline \multicolumn{6}{|c|}{ Bactimos briquets } \\
\hline Treatment & 724 & $36.2^{\mathrm{a}} \pm 9.3$ & 636 & 87.8 & \multirow{2}{*}{5.1} \\
\hline Control & 812 & $40.6^{a} \pm 10.1$ & 753 & 92.5 & \\
\hline \multicolumn{6}{|l|}{ Spinosad tablets } \\
\hline Treatment & 533 & $26.7^{\mathrm{a}} \pm 10.8$ & 447 & 83.9 & \multirow{2}{*}{7.4} \\
\hline Control & 756 & $37.8^{b} \pm 9.5$ & 685 & 90.6 & \\
\hline \multicolumn{6}{|l|}{ Altosid briquets } \\
\hline Treatment & 564 & $28.2^{\mathrm{a}} \pm 10.8$ & 435 & 77.1 & \multirow{2}{*}{15.5} \\
\hline Control & 827 & $41.3^{\mathrm{b}} \pm 11.1$ & 764 & 91.2 & \\
\hline \multicolumn{6}{|l|}{ Dudim tablets } \\
\hline Treatment & 508 & $25.4^{\mathrm{a}} \pm 9.7$ & 367 & 72.2 & \multirow{2}{*}{22.9} \\
\hline Control & 792 & $39.6^{\mathrm{b}} \pm 10.3$ & 742 & 93.7 & \\
\hline
\end{tabular}

* Mean of 20 engorged mosquito females; means of each formulation followed by the same letter are not significantly different $(\mathrm{P}=0.05)$.

The reduction in this mean per female was about $10.8 \%$. However, larval treatments with SRFs of Spinosad, Altosid and Dudim caused a marked decrease in the egg-laying capacity of $A$. aegypti female survivors. The mean number of eggs/ female in the above SRF treatments was in respect 26.7, 28.2 and 25.4 eggs as compared with their controls $37.8,41.3$ and 39.6 eggs, respectively. The records thus indicate that larval treatments with these SRFs caused about $29.5,31.8$ and $35.9 \%$ reduction in egg production of female survivors. Statistically, the records showed that the differences in the mean number of eggs between treatment trials and control ones were significant. Moreover, the results presented in Table 4 indicated that the hatchability of eggs produced by $A$. aegypti females that emerged from larval treatments with Bactimos briquets $(87.8 \%)$, Spinosad tablets $(83.9 \%)$, Altosid briquets $(77.1 \%)$ and Dudim tablets $(72.2 \%)$ was reduced as compared with their controls $(92.5,90.6$, 91.2 and $93.7 \%$ ) by about 5.1, 7.4, 15.5 and $22.9 \%$, respectively. A possible explanation is that the exposure of mosquito larvae to residues of SRFs for long periods may be affect its gonads and accordingly the reproductive capacity of adult survivors (Robert and Olsom, 1989; Vasuki, 1999; Saleh et al., 2013). However, long term follow-up studies are needed to determine how physico-chemical factors (i.e.; water $\mathrm{pH}$, high organic matter contents, water temperature and sunlight) affect the larvicidal effectiveness of such SRFs when used for field control measures.

\section{REFERENCES}

Abbott, W.S. (1925). A method of computing the effectivenss of an insecticide. J. Econ. Entomol. 18: 256-269.

Bond J.G, C.F. Marina and C.F. Williams (2004). The naturally derived insecticides spinosad is highly toxic to Aedes and Anopheles mosquito larvae. Med Vet.Entomol 18: 50-56.

Cornel, A., J. Stanich; D. Farey; F.S. Mulligan, and G. Byde (2000). Methoprene tolerance in Aedes nigromoculis in Frenso country, California, J. Am. Mosq. Control. Assoc., 16 (3): 233-228. 
Darriet, F.; S. Marcoinbe; M. Etienne, A. Yebakima; P. Agenew; M. YPTcha and V. Corbet (2010). Field evaluation of Pyriproxyfen and Spinosad mixture for the control of insecticide- resistant Aedes aegypti in Martinique (French west Indies). Parasites of vectors. 3: 88.

Jacups, S.P.; C.J. Paton and S.A. Ritchie (2014). Residual and pretreatment application of starycide insect growth regulator (triflumuron) to control Aedes aegypti in containers. Pest Manag Sci. 70 (4): 572-575.

Knepper, R.G.; A.D. Strickler and E.D. Walker (1992). Evalution of Methorpene (Altosid) sustained-release briquets for control of Culex mosquitoes in urban catch basins. J. Am. Mosq. Control Assoc. 8 (3): 228-230.

Mulla, M.S.; H.A. Darwazeh and H. Axelrod (1988). Activity of slow release formulations of IGRs fenxycarb and Altosid against mosquitoes and non-target aquatic organisms. Proceeding and papers of the $56^{\text {th }}$ Ann. Conf. of California Mosquito and vector cont. Assoc. 184-191.

Nasei, R.S.; G.B. Wright and F.S. Willis (1994). Control of Aedes allopictus larvae using time-release larvicide formulations in Louisiana. J. Am. Mosq. Cont. Assoc. 10 (10): 1-6.

Nayer, J.K.; A. Ali and M. Zaim (2002). Effectiveness and residual activity comparison of granular formulations of insect growth regulators pyriproxyfen and S-methoprene against Florida mosquitoes in laboratory and outdoor conditions. J. Am. Mosq Cont. Assoc. 18(3): 196-201.

Robert, L.L. and J. K. Olson (1989). Effects of sublethal dosages of insecticides on Culex quinquefasciatus. J. Am Mosq. Control. Assoc, 5, 239-246.

Saleh, M.S. and R.E. Wright (1990). Evaluation of the IGR cyromazine as a feed-through treatment against Culex pipiens and Aedes epacticus. J. App. Ent. 109: 247-250.

Saleh, M.S.; N.L. Kelada; F.A. El-Meniawi and H.M. Zahran (2003). Bacillus thuringiensis var. israelensis as sustained-release formulations against the mosquito Culex pipiens with especial reference to the Larvicidal effects of the bacterial agent in combination with three chemical insecticides. Alex. J. Agric. Res. 48(1): 53-60.

Saleh, M.S.; O.A. Abuzinadah,; KH. M. Al-Gamdi, A.A. Alsagaf and J.A. Mahyoub (2013). Effectiveness of slowrelease tablet formulations of the IGR diflubenzuron and the bioinsecticide Spinosad against larvae of Aedes aegypti (L.). African Entomology 21 (2): 349-355.

Seng, C.M.; Setha; J. Nealon; D.S. Socheat and M.B. Nathasn (2008). Six months of Aedes aegypti control with a novel controlled-release formulations of pyriproxyfen in domestic water storage containers in Combodia. South. Asian J. Trop. Med. Pub. Heath. 39(5): 822-826.

Sithiprasasna, R.; E. Luepromchai and K.J. Linthicum (1996). Effects of sublethal dosages of methoprine on Anopheles dirus species A and B. J. Am. Mosq. Control Assoc. 12 (13): 483-486.

Thavara, U.; A. Tawatsin; P. Asavadachnukorn and M. Mulla (2009). Field evaluation in Thailand of Spinosad a larvicide derived from Saccharospora spinosa (Actinomycetes) against Aedes aegypti (L.) larvae. Southeast Asian J. Trop. Med. \& Public Health, 40: 235242.

Tripathi, A.; A.B. Hadapad; R.S. Hire, J.S. Melo and S.F. D'Souza (2013). Polymeric macroporous formulations for the control release of ISPC-8. Enzyme and Microbial Tech. 53: 398-405.

Vasuki, V. (1992). The effects of sublethal doeses of hexaflumuron on the feeding behavior of mosquitoes (Diptra: Culicidae). Bull Ento. Res. 82: 532-538.

Vasuki, V. (1999). Influence of IGR treatments on oviposition of three speices of vector mosquitoes at sublethal concentrations. Southeast Asia J. Trop. Med. \& Public Health, 30: 200-203.

World Health Organization (2005). Prevention and control dengue and dengue hemorrhagic fever. WHO, Regional publication, searl no. 29. 134 pgs.

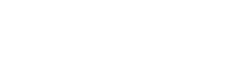

\section{قيمشبه جقلي لبهن تجههيزل المبيدك الهشربة بليئة الانسيلب ضد بهوضنة حم الضك Aedes aegypti ناصر بن أحمد الكنافي، خالد بن محمد الغلمدي، مصطفسليمان صالح، جازم عبد الـمهيوب}

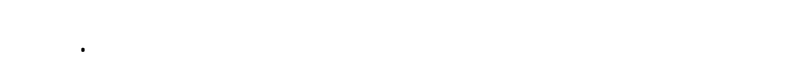

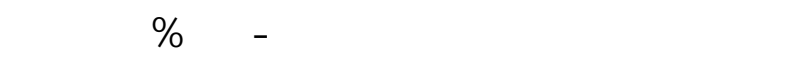

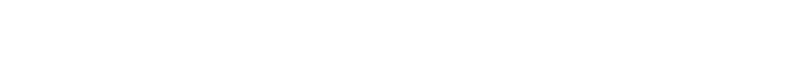

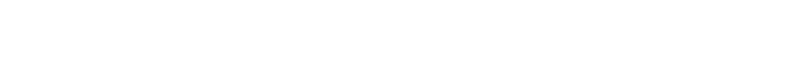
بكتيموس، أسبينوساد، ألتوسيد، دوديم على التوالي.
لجريت تجارب شببه حقلية لقفي سم فاعلي ـة تتجهي -زات

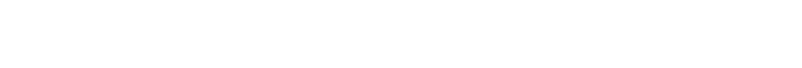

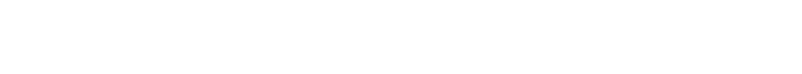

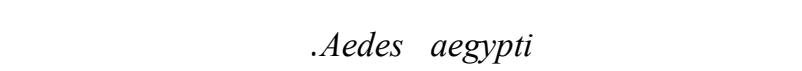
المعلملة بالتجهيزات بطيئة الانسيب مرة ولحة قد أعط ـت 
من نلحية أخرى، أظطهرت النتائج أن المعلملات اليرقية

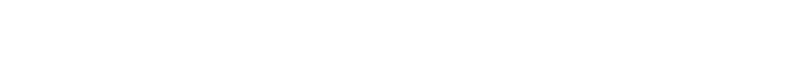

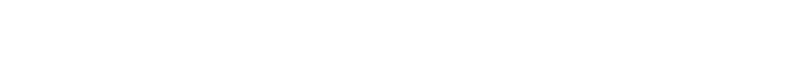
علش من ناك المعلملات. 